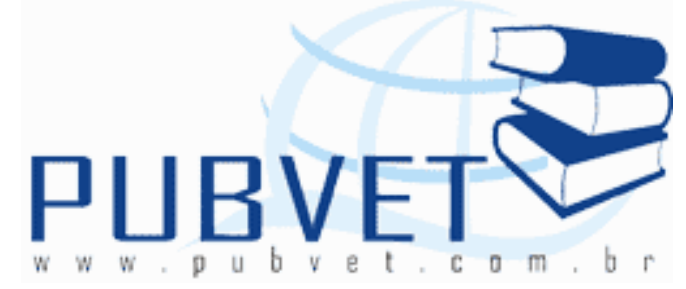

PUBVET, Publicações em Medicina Veterinária e Zootecnia.

\title{
Erliquiose monocítica canina: epidemiologia, imunopatogênese e diagnóstico
}

Juliana Pierangeli Fonseca ${ }^{1}$, Christian Hirsch ${ }^{2}$, Antônio Marcos Guimarães ${ }^{2}$

1 Mestre em Ciências Veterinárias - Universidade Federal de Lavras - UFLA ${ }^{2}$ Professor Doutor - Universidade Federal de Lavras - UFLA

\section{Resumo}

O propósito deste estudo é apresentar uma revisão sobre erliquiose monocítica canina (EMC), com ênfase na epidemiologia, imunopatogênese e diagnóstico. A doença é causada pela Ehrlichia canis, bactéria Gram negativa, intracelular obrigatória, transmitida pelo carrapato vetor Rhipicephalus sanguineus ("carrapato marrom do cão"). EMC é uma doença cosmopolita de grande relevância na clinica veterinária, com manifestações clínicas inespecíficas e multissistêmicas, e pode apresentar três formas: aguda, subclínica ou crônica. A erliquiose pode acometer cães de ambos os sexos e diferentes raças e idades, e tem como principal fator de risco a exposição ao carrapato vetor. Os sinais clínicos são consequência da resposta imunológica em função da infecção. O diagnóstico clínico é difícil e os sinais clínicos são facilmente confundíveis com outras doenças. A EMC apresenta alta morbidade e mortalidade, e o sucesso do tratamento depende da precocidade do diagnóstico, de uma terapia eficaz e do controle do carrapato vetor.

Palavras-chave: cães, Ehrlichia canis, Rhipicephalus sanguineus, trombocitopenia, anemia. 


\title{
Erlichiosis canine: Epidemiology, immunopathogenesis and diagnosis
}

\begin{abstract}
This purpose of this study is to describe a review about the canine monocytic ehrlichiosis (CME), with emphasis on epidemiology, immunopathogenesis and diagnosis. The disease is caused by Ehrlichia canis, Gram negative bacterium, obligate intracellular, transmitted by the tick vector Rhipicephalus sanguineus (brown dog tick). CME is worldwide distribution disease of great importance in a veterinary medicine, the clinical manifestations are nonspecific and multisystemic, and may have three forms: acute, subclinical and chronic. The ehrlichiosis can affect dogs of both sexes and different breeds and ages, and its main risk factor is exposure to the tick vector. The clinical signs observed are a consequence of the immune response due the infection. The clinical diagnosis is difficult and the clinical symptoms are easily confused with other diseases. The CME has a high morbidity and mortality, and the successful of treatment depends on early diagnosis, effective therapy and control of tick vector.
\end{abstract}

Keywords: dogs, Ehrlichia canis, Rhipicephalus sanguineus, thrombocytopenia, anemia.

\section{INTRODUÇÃO}

Erliquiose monocítica canina (EMC), doença cosmopolita, cujo agente etiológico primário é Ehrlichia canis (Rickettsiales: Anaplasmataceae), bactéria Gram negativa intracelular obrigatória, é transmitida pelo carrapato vetor Rhipicephalus sanguineus (DANTAS-TORRES, 2008). Considerada como uma das principais doenças infecciosas que acometem os cães, a EMC desperta um grande interesse veterinário e de saúde pública, pois além dos aspectos relacionados à saúde animal, é reconhecida como potencial agente zoonótico (PEREZ; WEN, 1996; PEREZ et al., 2006; STICH et al., 2008). 

2013.

Também conhecida como pancitopenia tropical canina, a EMC apresenta uma grande variedade de sinais clínicos e achados laboratoriais inespecíficos, em diferentes fases da doença (aguda, subclínica ou crônica), tal como febre, depressão, dispneia, anorexia, linfoadenopatia, anemia, leucopenia, trombocitopenia, hipergamaglobulinemia, petéquias, equimoses na pele, uveíte anterior e opacidade da córnea (BREITSCHWERDT, 2004).

Os cães infectados com E. canis apresentam alterações clínicas, hematológicas e bioquímicas bastante inespecíficas, o que dificulta o diagnóstico. Portanto, o diagnóstico presuntivo deve ser firmado com base nos sinais clínicos e nos exames laboratoriais. Porém, o diagnóstico conclusivo depende da visualização de mórulas em monócitos e linfócitos, da determinação de altos títulos de anticorpos anti-E. canis ou da detecção de DNA de E. canis pela PCR (reação em cadeia da polimerase) (AGUIRRE et al., 2004; SOUSA et al., 2010; UENO et al., 2009; WANER et al., 2001).

O cultivo em célula in vitro da $E$. canis permitiu a utilização da reação de imunofluorescência indireta (RIFI), tanto na pesquisa como na titulação de anticorpos desta riquétsia, sendo uma das técnicas sorológicas mais utilizadas no diagnóstico e na pesquisa da EMC. A RIFI, descrita por Ristic e colaboradores em 1972, é considerada, correntemente, como "padrão ouro", sendo utilizada como referência para avaliação de outras técnicas sorológicas de diagnóstico (LÓPEZ et al., 2007; WANER et al., 2001).

Entretanto, a possibilidade de ocorrer reação cruzada entre $E$. canis e $E$. chaffeensis (RIKIHISA et al., 1992; WANER et al., 2001), associado à persistência de títulos de anticorpos pós-tratamento, são limitações da RIFI, que podem comprometer a interpretação do resultado sorológico, sendo necessária à utilização de outros testes mais específicos para a identificação do agente etiológico, como por exemplo, a PCR (NEER et al., 2002).

O conhecimento sobre a imunopatologia relacionada com a infecção por E. canis ainda é limitado (COHN, 2003). Alguns cães são assintomáticos e em outros as manifestações clínicas são inespecíficas e muitas vezes acometem diferentes sistemas. As alterações hematológicas durante a infecção são 
destacadas por trombocitopenia e leucopenia (HARRUS; WANER, 2011; UENO et al., 2009; WANER et al., 1997).

Considerada uma doença cosmopolita, a EMC é particularmente mais prevalente em regiões tropicais e subtropicais. No Brasil, a ocorrência da erliquiose canina vem aumentando expressivamente em várias regiões e coincide com a distribuição do carrapato vetor $R$. sanguineus, que se encontra amplamente distribuído por diversas áreas urbanas no país (LABRUNA; PEREIRA, 2001).

Em função da relevância e do interesse cada vez maior que essa doença vem despertando no âmbito da clínica veterinária, o objetivo desta revisão é enfatizar os principais pontos relacionados a epidemiologia, imunopatogênese e diagnóstico da erliquiose monocítica canina (EMC).

\section{REVISÃO DE LITERATURA}

\section{Epidemiologia}

Ehrlichia canis é transmitida pelo carrapato $R$. sanguineus (Acari: Ixodidae), que se infecta ao ingerir sangue com monócitos e linfócitos parasitados por esta riquétsia durante o repasto sanguíneo, geralmente na fase aguda da doença, (RIKIHISA, 1991).

No carrapato, E. canis se multiplica nas células epiteliais do intestino, hemócitos e na glândula salivar. Ocorre transmissão transestadial, mas não transovariana, sendo o cão o principal reservatório do agente. Essa riquétsia pode ser transmitida para os cães por ninfas e adultos de $R$. sanguineus (GROVES et al., 1975), e de forma intraestadial por machos adultos do carrapato (BREMER et al., 2005). No momento do repasto sanguíneo, o carrapato inocula $E$. canis juntamente com a saliva (RIKIHISA, 1991). O ixodídeo infectado pode transmitir $E$. canis por até cinco meses após adquirir a infecção (DAGNONE et al., 2001; DANTAS-TORRES, 2008; RIKIHISA, 1991). 

2013.

Embora a EMC seja uma doença cosmopolita, é particularmente mais prevalente em regiões tropicais e subtropicais (LITTLE, 2010). Estudos sorológicos, citológicos e moleculares têm apresentado evidências de cães infectados por E. canis na África, Ásia, Europa, e América do Norte, Central e do Sul (STICH et al., 2008).

No Brasil, a erliquiose canina foi diagnosticada pela primeira vez em 1973, em um cão oriundo de Belo Horizonte, MG (COSTA et al., 1973). A presença de cães infectados com $E$. canis tem sido demonstrada em estudos realizados na região Sul (DAGNONE et al., 2003; TRAPP et al., 2006), Sudeste (ALBERNAZ et al., 2007; BULLA et al., 2004; COSTA JúNIOR et al., 2007; MACIEIRA et al., 2005; MOREIRA et al., 2003; SANTOS et al., 2009); Nordeste (CARLOS et al., 2007; SOUZA et al., 2010), Norte (AGUIAR et al., 2007), com a prevalência variando de 14 a $45 \%$ dos cães atendidos em hospitais e clínicas veterinárias.

A prevalência da erliquiose canina pode variar em função do clima, devido a certos fatores epidemiológicos (distribuição do vetor, modo de vida dos cães e a idade da população experimental) e as práticas de manejo e o habitat dos animais (KEEFE et al., 1982; RODRIGUEZ-VIVAS; ALBERNOZ; SAINZ et al., 1996).

O principal fator de risco para a infecção por $E$. canis no país é a exposição direta dos cães ao $R$. sanguineus (AGUIAR et al., 2007; CARLOS et al., 2011; CARVALHO et al., 2008; COSTA JÚNIOR et al., 2007; DAGNONE et al., 2001; TRAPP et al., 2006), espécie de carrapato predominante entre os animais criados em áreas urbanas com uma prevalência de infestação em torno de 30\% (SZABÓ et al., 2001).

Rhipicephalus sanguineus constitui o principal transmissor da EMC no país, não sendo observada a presença de $E$. canis infectando outras espécies de ixodídeos no território nacional (LABRUNA et al., 2007). No Brasil, Aguiar et al. (2007) encontraram uma frequência de $R$. sanguineus naturalmente infectado com $E$. canis entre 2,3 a 6,2\%. No país, foram identificados pela primeira vez carrapatos $R$. sanguineus naturalmente infectados por $E$. canis, 

2013.

coletados de cães provenientes dos estados de Rondônia e São Paulo, por meio da PCR para um fragmento do gene dsb de Ehrlichia. Também nesse estudo, observou-se que a soroprevalência de $E$. canis, por meio da RIFI, é maior em cães criados em área urbana (37,9\%) em relação aos animais mantidos na zona rural $(24,8 \%)$, no município de Monte Negro, Rondônia (AGUIAR et al., 2007). Entretanto, devido às condições socioeconômicas dos proprietários, responsável pela restrição orçamentária, o que compromete o controle dos carrapatos, os cães criados em áreas rurais estão mais expostos à infecção por E. canis (RODRIGUEZ-VIVAS, 2005).

\section{Imunopatogênese}

Mecanismos imunológicos relacionados à citotoxicidade dependente de anticorpos estão envolvidos na patogenia da erliquiose canina (HARRUS; WANER; BARK, 1997).

A imunopatogênese dessa doença, contudo, ainda é pouco conhecida, e o seu melhor entendimento contribui para o diagnóstico, prognóstico, prevenção e controle (HARRUS; WANER, 2011; SHIPOV et al., 2008). Acredita-se que o mecanismo de resposta protetora predominante é T-dependente e com elevada concentração de INF-Y. Em cães, infectados experimentalmente com E. canis, observa-se anticorpos específicos das classes IgM e IgA quatro a sete dias após a infecção (DAI) e IgG, 15 DAI (WANER et al., 2001). Algumas manifestações clínicas da erliquiose canina são mediadas por imunocomplexos (HARRUS et al., 2001).

Os monócitos e macrófagos são importantes células do sistema imunológico com funções relacionadas à fagocitose, apresentação de antígenos a células do sistema imune adaptativo, produção de citocinas próinflamatórias, remodelação tecidual e regulação da imunidade inata e adaptativa, entre outras (WERMELING; KARLSSON). Ehrlichia canis compromete a resposta de defesa do organismo, entre outros fatores, pela infecção das células fagocíticas mononucleares (KAKOMA; CARSON; RISTIC, 
FONSECA, J.P., HIRSCH, C. e GUIMARÃES, A.M. Erliquiose monocítica canina: epidemiologia, imunopatogênese e diagnóstico. PUBVET, Londrina, V. 7, N. 8, Ed. 231, Art. 1529, Abril, 2013.

1980), um importante mecanismo de escape imunológico que ainda não está bem esclarecido.

Os mecanismos seguintes à penetração da célula hospedeira são responsáveis pela mudança no ambiente humoral e celular. Imunofenotipagem de seções dos linfonodos e baço revelaram alterações nas populações de células CD3+ e CD8+, além de aumento das concentrações de IgM e IgG em cães infectados com $E$. canis (CASTRO et al., 2004).

A manutenção da fase aguda por E. canis mostrou uma queda dos elementos celulares, com acentuada queda nas subpopulações de linfócitos $T$ CD4+, MHC II+ e CD45R+, situação que determina imunossupressão pela perda fisiológica na habilidade de reconhecimento antigênico e ativação da resposta imune adaptativa (HARRUS et al., 2003; MOREIRA, 2005).

A patogenia da erliquiose canina esta relacionada em grande parte a intensa vasculite que pode ocorrer e, como consequência, é observado nefrite intersticial, inflamação perivascular no fígado com presença de degeneração hidrópica, meningo-encefalite não supurativa, esplenomegalia e hiperplasia de cordões medulares (CASTRO et al., 2004).

A anemia observada na EMC esta associada à supressão da eritropoese pela medula óssea, lise celular mediada pelo sistema complemento e efeito do sistema fagocítico mononuclear (MOREIRA et al., 2003). A trombocitopenia, achado corrente na infecção por E. canis, deve-se ao consumo e destruição de plaquetas, sequestro de plaquetas pelo baço, diminuição da produção de plaquetas em função da hipoplasia da medula óssea (WOODY; HOSKINS, 1991) e produção de anticorpos antiplaquetas (GAUNT et al., 2010).

\section{Diagnóstico}

Os cães infectados com E. canis apresentam alterações clínicas, hematológicas e bioquímicas bastante inespecíficas, e o diagnóstico presuntivo pode ser firmado com base no histórico epidemiológico relatado na anamnese, nos sinais clínicos e nos exames laboratoriais. Porém, sua confirmação 
(diagnóstico conclusivo) depende da visualização de mórulas em monócitos e linfócitos, da determinação de altos títulos de anticorpos anti-E. canis e/ou da detecção de DNA de E. canis pela PCR (SOUSA et al., 2010).

\section{Clínico}

A erliquiose monocítica canina (EMC), como obervado em infeç̧ões experimentais, apresenta três fases clínicas: aguda, subaguda e crônica. Após um período de incubação de oito a vinte dias, E. canis multiplica-se em linfócitos e monócitos circulantes, linfonodos e vísceras (fígado e baço), induzindo linfoadenomegalia e hiperplasia linforreticular, e diversos sinais sistêmicos, iniciando a fase aguda da doença. Nessa fase, os sinais clínicos são geralmente inespecíficos, incluindo pirexia, anorexia, depressão, letargia, perda de peso, linfoadenomegalia, esplenomegalia, pneumonite e alterações oculares como uveíte anterior e opacidade da córnea (BREITSCHWERDT, 2004).

As células infectadas por $E$. canis são carreadas por meio da circulação sanguínea para diversos órgãos, principalmente pulmões, rins e meninges, e ocorre aderência ao endotélio vascular, causando vasculite e infecção tecidual subendotelial. O consumo, sequestro e destruição das plaquetas induzem a trombocitopenia observada na fase aguda. A trombocitopenia é comum, mas as petéquias podem não estar evidentes e a queda no número de plaquetas em alguns animais pode ser discreta. Vasculites e mecanismos imunomediados induzem a trombocitopenia e tendências à hemorragia. Na fase aguda, a contagem de leucócitos é variável (leucocitose ou leucopenia), e a anemia, devido à supressão da produção de eritrócitos e à destruição acelerada das hemácias, desenvolve-se progressivamente (ALMOSNY, 2002; ETTINGER; FELDMAN, 2004). Os sinais clínicos da fase aguda podem ser mais graves dependendo da virulência da cepa de $E$. canis e parecem ser exacerbados na presença de coinfecções com outros agentes, também transmitidos pelo 

2013.

mesmo carrapato vetor, como outras riquétsias e protozoários (GAL et al., 2007; UNVER et al., 2008).

A despeito da gravidade da fase aguda em alguns casos, incluindo até a morte, vários cães parecem tolerar bem a infecção por E. canis sem apresentar sinais clínicos evidentes da doença. Esses animais passam para a fase subclínica da EMC na qual podem permanecer meses ou anos cronicamente infectados, mas sem sinais evidentes dessa enfermidade. Nessa fase, o agente persiste intracelularmente, e os cães podem apresentar trombocitopenia branda, leucopenia e anemia. Devido à deposição de imunocomplexos, alguns animais poderão apresentar glomerulonefrite. Na fase subclínica, os cães imunocompetentes podem eliminar $O$ agente e se recuperarem, sem desenvolverem a fase crônica (BREISTSCHWERDT, 2004; HARRUS et al., 1998; WANER et al., 1997).

$\mathrm{Na}$ fase crônica, os sinais clínicos são ausentes ou discretos em alguns cães. Entretanto, em outros animais os sinais podem ser graves e potencialmente fatais. Os achados clínicos podem variar de acordo com os órgãos predominantemente afetados: esplenomegalia, glomerulonefrite, insuficiência renal, pneumonite interticial, uveíte anterior, meningite associada à ataxia cerebelar, depressão, paresia, hiperestesia, anorexia e perda de peso. Nessa fase pode ocorrer pancitopenia (BREITSCHWERDT, 2004; STICH et al., 2008). Frequentemente, a trombocitopenia grave pode causar: epistaxes, petéquias ou equimoses hemorrágicas, melena e hematúria, hifema, hemorragia da retina e uveíte anterior (NEER; HARRUS, 2006).

As alterações hematológicas e bioquímicas observadas na EMC podem variar de acordo com a fase da doença. Na aguda, trombocitopenia, pancitopenia, hipoalbuminemia, hiperglobulinemia, hipergamaglobulinemia, e aumentos discretos da alanino amino transferase (ALT) e fosfatase alcalina (FA) são frequentes (STICH et al., 2008). A trombocitopenia geralmente é acompanhada de anemia branda e redução discreta na contagem de leucócitos, se comparado com os valores na pré-infecção (HARRUS; WANER, 2011). 

2013.

$\mathrm{Na}$ fase subclínica, uma trombocitopenia branda pode estar presente, mesmo na ausência de sinais clínicos. Já na fase crônica, a trombocitopenia geralmente é grave e acompanhada de uma acentuada anemia e leucopenia (HARRUS; WANER; BARK, 1997). Em um estudo retrospectivo de casos letais em cães diagnosticados com EMC na forma clínica crônica, observou-se marcada pancitopenia (devido à hipoplasia de medula óssea), anorexia, depressão, grave tendência a sangramentos, hipoalbuminemia e aumento da ALT (MYLONAKIS et al., 2004).

\section{Laboratorial}

\section{Citológico}

Nos cães, E. canis forma inclusões intracelulares denominadas de mórulas, que podem ser detectadas em monócitos e linfócitos no sangue periférico e em aspirados de nódulos linfáticos. Utilizando corantes de rotina, a mórula se apresenta como uma estrutura arredondada, formada por um conjunto de vários corpúsculos corados em roxo, medindo de um a vários micrômetros de diâmetro, dentro de um vacúolo ( HARRUS; WANER; 1997).

Embora apresentando uma forma bem característica e de fácil diagnóstico, poucas mórulas são ocasionalmente visíveis na fase aguda da EMC, podendo gerar muitos resultados falso-negativos. De acordo com HARRUS; WANER; BARK, (1997), estas estruturas são encontradas em apenas $4 \%$ dos casos positivos ou frequências ainda mais baixas, principalmente na fase subclínica (HARRUS; WANER, 2011), que segundo WANER (2008), seria quando a $E$. canis, provavelmente, estaria retida no baço e então não poderia ser detectada na circulação.

Assim, uma das formas de aumentar a eficácia do diagnóstico citológico é proceder ao exame de 1000 campos microscópicos do concentrado leucocitário (capa leucocitária) ou de material obtido de aspirados da medula óssea corados com Giemsa, que pode alcançar uma sensibilidade de $66 \%$ e 
$61 \%$, respectivamente, porque mais leucócitos podem ser examinados por lâmina. Desse modo, o exame do concentrado leucocitário pode ser utilizado como método de rotina para o diagnóstico citológico da EMC, principalmente em cães que não apresentam linfadenopatia periférica, pois nesses casos deve-se proceder a pesquisa de mórula no material obtido por meio da punção aspirativa do nódulo linfático (MYLONAKIS et al., 2003).

\section{Sorológico}

O diagnóstico da EMC é geralmente baseado na sorologia, utilizando testes como a reação de imunofluorescência indireta (RIFI), ELISA e Western imunoblotting (WANER et al., 2001), já que os aspectos clínicos e clínicopatológicos são altamente inespecíficos (SOUSA et al., 2010). No entanto, em áreas de alta endemicidade para EMC o diagnóstico sorológico positivo não é conclusivo, não só por causa dos sinais clínicos inespecíficos, mas devido ao fato dos cães poderem manter altos títulos de anticorpos anti-E. canis durante meses ou anos, mesmo após um tratamento bem sucedido ou a eliminação do agente pelo sistema imune do hospedeiro (BARTSCH; GREENE, 1996; HARRUS et al., 1998; NEER et al., 2002; WANER et al., 2001).

A RIFI para a pesquisa de anticorpos IgG anti-E. canis é considerada o método sorológico "padrão ouro" ("gold standard"), indicando exposição ao agente (HARRUS; WANER, 2011). Na interpretação de um resultado de RIFI, além do título de anticorpos anti-E. canis, deve-se levar em consideração os sinais clínicos e os parâmetros hematológicos sugestivos da doença. Um cão com sorologia positiva é sugestivo de exposição a $E$. canis (WANER et al., 2001).

Uma das limitações da RIFI é que pode ocorrer reação cruzada entre E.canis, E. ewingii e E. chaffeensis, e outras espécies de Ehrlichia, gerando resultados falso-positivos. Por outro lado, na fase aguda da EMC, podem ocorrer resultados falso-negativos quando os cães falham na produção de anticorpos ou encontram-se nos primeiros dias pós-infecção (CARDENAS et al., 

2013.

2007; NEER et al., 2002; WEN et al., 1997). Entretanto, não ocorre reação cruzada para Anaplasma platys, agente etiológico da trombocitopenia cíclica canina (FRENCH; HARVEY, 1983).

\section{Reação em cadeia da polimerase (PCR)}

\section{Baseado na Região 16S rRNA}

Para a identificação em nível de gênero, é possível o uso de PCR direcionada para amplificação de segmentos do gene 16S rRNA (GREISEN et al., 1994) ou do gene rRNA 235 (VAN CAMP et al., 1993). O DNA amplificado, uma vez sequenciado, contem informações que permite a identificação do gênero da bactéria, por meio do cálculo algorítmo empregado no programa "BlastN", disponível no National Centre of Biotechnology Information (NCBI), que compara a sequência obtida com as sequências depositadas no banco mundial de genomas GenBank (BENSON et al., 2011). Diversos trabalhos já utilizaram a PCR como ferramenta de diagnóstico e de investigação genética do gênero Ehrlichia. O alvo mais amplamente usado é o gene que codifica o 16S rRNA (HARRUS e WANER, 2011).

Devido a sensibilidade e especificidade diagnóstica da PCR direcionada para a região 16S rRNA DNA de espécies do gênero Ehrlichia e sua aplicabilidade nos estudos epidemiológicos desse gênero, diversos outros autores utilizaram-se desta ferramenta para pesquisa, nas duas últimas décadas. Parasitos deste gênero foram assim caracterizados em diversas espécies de hospedeiros, tais como cães (ENGVALL et al., 1996; ALEXANDRE et al., 2009; BANETH et al., 2009; FARIA et al., 2010), bovinos e equínos (ENGVALL et al., 1996), felinos selvagens brasileiros (ANDRÉ et al., 2010) e guaxinins (Procyon lotor) (SASHIKA et al., 2011). 


\section{Baseado no gene GP200}

As sequências genéticas da região 16S rRNA DNA caracterizam-se por sua estabilidade e, portanto, são úteis em métodos diagnósticos moleculares direcionadas à detecção de gêneros de bactérias. Entretanto, esta propriedade limita os resultados quando se pretende caracterizar espécies ou variantes dentro de um mesmo gênero. Dessa forma o gene GP200 permite identificação em nível de espécie.

O gene de E. canis GP200 é composto por $4.263 \mathrm{pb}$ e origina um polipeptídeo com 1.421 aminoácidos. Quatro subregiões gênicas foram caracterizadas: porção N-terminal (terminação amina), com $1.107 \mathrm{pb}$; porção interna amina (N), com 910pb; porção interna carboxila (C), com 1.000 pb e porção C-terminal (terminação carboxila), com 1.280pb (NETHERY et al., 2007)

Segundo esses autores, o produto destas subregiões gênicas é um polipeptídeo com três regiões que são reconhecidas fortemente por anticorpos (consideradas regiões imunodominantes): sequências peptídicas $\mathrm{N}$-terminal, Cinterno e C-terminal, com 369, 332 e 426 aminoácidos, respectivamente. Outro estudo demonstrou que existe uma associação entre uma forte resposta imunológica contra esta glicoproteína e outras glicoproteínas de $E$. canis e a fase de convalescença da doença. Provavelmente, a imunidade contra gp200 é importante para a recuperação dos animais e, possivelmente, para a prevenção, caso utilizada em vacinas (McBRIDE et al., 2001; McBRIDE et al., 2003). Estes dados reforçam o interesse no estudo genético de GP200 de amostras brasileiras, uma vez que caracterizam esta glicoproteína como eletiva para imunização e para atuar como antígeno em testes imunodiagnósticos.

\section{CONCLUSÕES}

A Erliquiose Monocítica Canina (EMC), causada pela E. canis, é uma doença infecciosa cosmopolita, transmitida pelo carrapato $R$. sanguineus, 
FONSECA, J.P., HIRSCH, C. e GUIMARÃES, A.M. Erliquiose monocítica canina: epidemiologia, imunopatogênese e diagnóstico. PUBVET, Londrina, V. 7, N. 8, Ed. 231, Art. 1529, Abril, 2013.

podendo acometer cães de diferentes raças e idades, e de ambos sexos. A exposição ao carrapato vetor é o principal fator de risco para a doença e mecanismos imunológicos relacionados à citotoxicidade dependente de anticorpos estão envolvidos na sua patogenia. Entretanto, a imunopatogênese da EMC ainda é pouco conhecida, e o seu melhor conhecimento contribui para o diagnóstico, prognóstico, prevenção e controle. O diagnóstico é difícil, pois além de não possuir sinais clínicos patognomônicos, apresenta sinais compatíveis com outras doenças infecciosas. No diagnóstico da EMC, além da sorologia positiva pela reação de imunofluorescência indireta (RIFI), citologia positiva (mórulas em monócitos e linfócitos), deve-se considerar os achados de trombocitopenia e anemia no hemograma, juntamente com as manifestações clínicas que são normalmente observadas nos casos clínicos da doença.

\section{REFERÊNCIAS BIBLIOGRÁFICAS}

AGUIAR, D. M. et al. Prevalence of Ehrlichia canis (Rickettsiales: Anaplasmataceae) in Dogs and Rhipicephalus sanguineus (Acari: Ixodidae) Ticks from Brazil. Journal of Medical

Entomology, Lanham, v. 44, n. 1, p. 126-132, 2007.

AGUIRRE, E. et al. First isolation and molecular characterization of Ehrlichia canis in Spain. Veterinary Parasitology, Amsterdam, v. 125, p. 365-372, 2004.

ANDRÉ, M.R. et al. Molecular and serologic detection of Ehrlichia spp. In endangered Brazilian wild captive felids. Journal Wildlife Diseases. v. 46, p.1017-23, 2010.

ALBERnAZ, A. P. et al. Erliquiose canina em Campos dos Goytacazes, Rio de Janeiro, Brasil. Ciência Animal Brasileira, Goiânia, v. 8, p. 799-806, 2007.

ALEXANDRE, N. et al. Detection of Ehrlichia canis by polymerase chain reaction in dogs from Portugal. The Veterinary Journal, London, v. 181, p. 343-344, 2009.

ALMOSNY, N. R. P. Hemoparasitoses em pequenos animais domésticos e como zoonoses. Rio de Janeiro: L. F Livros de Veterinária, 2002. Cap 1, p.16.

BANETH, G.; HARRUS, S.; OHNONA, F.S. et al. Longitudinal quantification of Ehrlichia canis in experimental infection with comparison to natural infection. Veterinary Microbiology, v. 136, p. 321-5, 2009.

BARTSCH, R. C.; GREENE, R. T. Post-therapy antibody titers in dogs with ehrlichiosis: followup study on 68 patients treated primarily with tetracycline and/or doxycycline. Journal of Veterinary Internal Medicine, Philadelphia, v. 10, p. 271-274, 1996. 
BREITSCHWERDT, E. B.; HEGARTY, B. C.; HANCOCK, S. I. Doxycycline hyclate treatment of experimental canine ehrlichiosis followed by challenge inoculation with two Ehrlichia canis strains. Antimicrobial Agents Chemotherapy, Bethesda, v. 42, p. 362-368, 1998.

BREITSCHWERDT, E. B. Riquetsioses. In: ETTINGER, S. J.; FELDMAN, E. C. Tratado de medicina interna veterinária: doenças do cão e do gato. 5. ed. Rio de Janeiro: Guanabara Koogan, 2004. p. 422-429.

BREMER, W. G. et al. Transstadial and intrastadial experimental transmission of Ehrlichia canis by male Rhipicephalus sanguineus. Veterinary Parasitology, Amsterdam, v. 131, p. 95-105, 2005.

BENSON, D.A. et al. GenBank. Nucleic Acids Research, v. 39, n. D32-7, 2011.

BULLA, C. et al. The relationship between the degree of thrombocytopenia and infection with Ehrlichia canis in an endemic area. Veterinary Research, Les Ulis, v. 35, p. 141-14, 2004.

CARDENAS, A. M. et al. Enzyme-linked immunosorbent assay with conserved immunoreactive glycoproteins gp36 and gp19 has enhanced sensitivity and provides species-specific immunodiagnosis of Ehrlichia canis infection. Clinical and Vaccine Immunology, Washington, v. 14, p. 123-128, 2007.

CARLOS, R. S. A. et al. Frequência de anticorpos anti-Erhlichia canis, Borrelia burgdorferi e antígenos de Dirofilaria immitis em cães na microrregião Ilhéus-Itabuna, Bahia, Brasil. Revista Brasileira de Parasitologia Veterinária, São Paulo, v. 16, p. 117-120, 2007.

CARLOS, R. S. A. et al. Risk factor and clinical disorders of canine ehrlichiosis in the South of Bahia, Brazil. Revista Brasileira de Parasitologia Veterinária, São Paulo, v. 20, p. 210214, 2011.

CARVALHO, F. S. et al. Epidemiological and molecular study of Ehrlichia canis in dogs in Bahia, Brazil. Genetic Molecular Research, Ribeirão Preto, v. 7, p. 657-662, 2008.

CASTRO, M. B. et al. Experimental acute canine monocytic ehrlichiosis: clinicopathological and immunopathological findings. Veterinary Parasitology, Amsterdam, v. 119, p. 73-86, 2004.

COHN, L. A. Ehrlichiosis and related infections. The Veterinary Clinics of North America Small Animal Practice, Philadelphia, v. 33, p. 863-884, 2003.

COSTA, J. O. et al. Ehrlichia canis infection in dog in Belo Horizonte, Brazil. Arquivo da Escola de Veterinária da Universidade Federal de Minas Gerais, Belo Horizonte, v. 25, p. 199200, 1973.

COSTA JÚNIOR, L. M. et al. Sero-prevalence and risk indicators for canine ehrlichiosis in three rural areas of Brazil. The Veterinary Journal, London, v. 174, p. 673-676, 2007.

DAGNONE, A. S. et al. Ehrlichiosis in anemic, thrombocytopenic, or tick-infested dogs from a hospital population in South Brazil. Veterinary Parasitology, Amsterdam, v. 117, p. 285-90, 2003.

DAGNONE, A. S.; MORAIS, H. S. A.; VIDOTTO, M. C. Erliquiose nos animais e no homem. Ciências Agrárias, Teresina, v. 22, p. 191-201, 2001. 
DANTAS-TORRES, F.; FIGUEREDO, L. A.; BRANDÃO FILHO, S. P. Rhipicephalus sanguineus (Acari:Ixodidae), the brown dog tick, paraziting humans in Brazil. Revista da Sociedade Brasileira de Medicina Tropical, Brasília, v. 39, p. 64-67, 2006.

DANTAS-TORRES, F. The brown dog tick, Rhipicephalus sanguineus (Latreille, 1806) (Acari: Ixodidae): from taxonomy to control. Parasitology, London, v. 152, p. 173-185, 2008.

ENGVALL, E.O. et al. A 16S rRNA-based PCR assay for detection and identification of granulocytic Ehrlichia species in dogs, horses, and cattle. Journal Clinical Microbiology, $v$. 34, p. 2170-4, 1996.

ETTINGER, S. J.; FELDMAN, E. C. Tratado de medicina interna veterinária: doenças do cão e do gato. 5. ed. Rio de Janeiro: Guanabara Koogan, 2004.

FARIA, J. L. M. et al. Ehrlichia canis morulae and DNA detection in whole blood and spleen aspiration samples. Revista Brasileira Parasitologia Veterinária, São Paulo, v. 19, p. 98$102,2010$.

FRENCH, T. W.; HARVEY, J. W. Serologic diagnosis of infectious cyclic thrombocytopenia in dogs using an indirect fluorescent antibody test. American Journal of Veterinary

Research, Chicago, v. 44, p. 2407-2411, 1983.

GAL, A. et al. Coinfection with multiple tick-borne and intestinal parasites in a 6-week-old dog. Canadian Veterinary Journal, Ottawa, v. 48, p. 619-22, 2007.

GAUNT, S. D. et al. Experimental infection and co-infection of dogs with Anaplasma platys and Ehrlichia canis: hematologic, serologic and molecular findings. Parasites and Vectors, London, v. 3, p. 33-42, 2010.

GREISEN, K.; LOEFFELHOLZ, M.; PUROHIT A. et al. PCR primers and probes for the 16S rRNA gene of most species of pathogenic bacteria, including bacteria found in cerebrospinal fluid. Journal Clinical Microbiology, v. 32, p. 335-51, 1994.

GROVES, M. G. et al. Transmission of Ehrlichia canis to dogs by ticks (Rhipicephalus sanguineus). American Journal of Veterinary Research, Chicago, v. 36, p. 937-940, 1975.

HARRUS, S. et al. Amplification of ehrlichial DNA from dogs 34 months after infection with Ehrlichia canis. Journal of Clinical Microbiology, Washington, v. 36, p. 73-76, 1998.

HARRUS, S. et al. Canine monocytic ehrlichiosis: a retrospective study of 100 cases, and an epidemiological investigation of prognostic indicators for the disease. Veterinary Record, London, v. 141, p. 360-363, 1997.

HARRUS, S. et al. Comparison of simultaneous splenic sample PCR with blood sample PCR for diagnosis and treatment of experimental Ehrlichia canis infection. Antimicrobial Agents and Chemotherapy, Washington, v. 48, p. 4488-4490, 2004.

HARRUS, S. et al. Comparison of three enzyme-linked immunosorbant assays with the indirect immunofluorescent antibody test for the diagnosis of canine infection with Ehrlichia canis.

Veterinary Microbiology, Amsterdam, v. 86, p. 361-368, 2002.

HARRUS, S. et al. Down-regulation of MHC class II receptors of DH82 cells, following infection with Ehrlichia canis. Veterinary Immunology and Immunopathology, Amsterdam, v. 96, p. 239-243, 2003. 
HARRUS, S. et al. Dynamics of IgG1 and IgG2 subclass response in dogs naturally and experimentally infected with Ehrlichia canis. Veterinay Parasitology, Amsteerdam, v. 99, p. 63-71, 2001.

HARRUS, S.; WANER, T.; BARK, H. Canine monocytic ehrlichiosis: an update. Compendium on Continuing Education for the Practicing Veterinarian, Princeton, v. 36, p. 431-447, 1997.

HARRUS, S.; WANER, T. Diagnosis of canine monocytotropic ehrlichiosis (Ehrlichia canis): an overview. The Veterinary Journal, London, v. 187, p. 292-296, 2011.

KAKOMA, I.; CARSON, C. A.; RISTIC, M. Direct and indirect lymphocyte participation in the immunity and immunopathology of tropical canine pancytopenia a review. Comparative Immunology, Microbiology and Infectious Diseases, Oxford, v. 3, p. 291-298, 1980.

KEEFE, T. J. et al. Distribution of Ehrlichia canis among military working dogs in the United States. Journal of American Veterinary Association, Chicago, v. 181, p. 236-238, 1982.

LABRUNA, M. B. et al. A preliminary investigation of Ehrlichia species in ticks, humans, dogs, and capybaras from Brazil. Veterinary Parasitology, Amsterdam, v. 143, p. 189-195, 2007.

LABRUNA, M. B.; PEREIRA, M. C. Carrapatos em cães no Brasil. Clínica Veterinária, Milano, v. 30, p. 24-32, 2001.

LITTLE, S. E. Ehrlichiosis and anaplasmosis in dogs and cats. Veterinary Clinical North American Small Practice, Suwon, v. 40, p. 1121-1140, 2010.

LÓPEZ, L. et al. Development of a sensitive and specific indirect enzyme-linked immunosorbent assay based on a baculovirus recombinant antigen for detection of specific antibodies against Ehrlichia canis. Journal of Veterinary Diagnostic Investigation, Columbia, v. 19, p. 635642, 2007.

MACIEIRA, D. B. et al. Prevalence of Ehrlichia canis infection in thrombocytopenic dogs from Rio de Janeiro, Brazil. Veterinary Clinical Pathology, Santa Barbara, v. 34, p. 44-48, 2005.

McBRIDE J. W. et al. Kinetics of antibody response to Ehrlichia canis immunoreactive proteins. Infection and Immunity, Washington, v. 71, p. 2516-2524, 2003.

McBRIDE J. W. et al. Immunodiagnosis of Ehrlichia canis infection with recombinant proteins. Journal of Clinical Microbiology, Washington, v. 39, p. 315-322, 2001.

MOREIRA, S. M. et al. Detection of Ehrlichia canis in bone marrow aspirates of experimentally infected dogs. Ciência Rural, Santa Maria, v. 35, n. 4, p. 958-960, 2005.

MOREIRA, S. M. et al. Estudo retrospectivo (1998-2001) da erliquiose canina em Belo Horizonte. Arquivo Brasileiro de Medicina Veterinária e Zootecnia, Belo Horizonte, v. 55, p. 141-147, 2003.

MYLONAKIS, M. E. et al. Chronic canine ehrlichiosis (Ehrlichia canis): a retrospective study of 19 natural cases. Journal American Animal Hospital Association, South Bend, v. 40, n. 3, p. 174-184, 2004.

MYLONAKIS, M. E. et al. Evaluation of cytology in the diagnosis of acute canine monocytic ehrlichiosis (Ehrlichia canis): a comparison between five methods. Veterinary Microbiology, Amsterdam, v. 91, p. 197-204, 2003. 
NEER, T. M. et al. Consensus statement on ehrlichial disease of small animals from the infectious disease study group of the ACVIM. Journal of Veterinary Internal Medicine, Philadelphia, v. 16, p. 309-315, 2002.

NEER, T. M.; HARRUS, S. Canine monocytotropic ehrlichiosis and neorickettsiosis (E. canis, $E$. chaffeensis, E. ruminantium, N. sennetsu, and N. risticii infections). In: GREENE, C. E. (Ed.). Infectious diseases of the dog and cat. 3rd ed. St Louis: S. Elsevier, 2006. p. 203-216.

NETHERY, K. A. et al. Ehrlichia canis gp200 contains dominant species-specific antibody epitopes in terminal acidic domains. Infection and Immunity, Washington, v. 75, p. 49004908, 2007.

PEREZ, M. et al. Human infection with Ehrlichia canis accompanied by clinical signs in Venezuela. Annals New York Academy of Sciences, New York, v. 1078, p. 110-117, 2006.

PEREZ, M.; RIKIHISA., Y.; WEN, B. Ehrlichia canis-like agent isolated from a man in Venezuela: antigenic and genetic characterization. Journal Clinical Microbiology, Washington, v. 34, p. 2133-2139, 1996.

REDDY, G. R. et al. Molecular characterization of a 28-kDa surface antigen gene family of the tribe Ehrlichiae. Biochemical and Biophysical Research Communications, Orlando, v. 247, p. 636-643, 1998.

RIKIHISA, Y. et al. Analyses of Ehrlichia canis and a Canine Granulocytic Ehrlichia Infection. Journal of Clinical Microbiology, Washington, v. 30, p. 143-148, 1992.

RIKIHISA, Y. The tribe Ehrlichieae and ehrlichial diseases. Clinical Microbiology Review, Washington, v. 4, p. 286-308, 1991.

SASHIKA, M.; ABE, G.; MATSUMOTO, K. et al. Molecular Survey of Anaplasma and Ehrlichia Infections of Feral Raccoons (Procyon lotor) in Hokkaido, Japan. Vector Borne Zoonotic Diseases. v. 11, p. 349-354, 2011.

SAINZ, A. et al. Seroprevalence of canine ehrlichiosis in Castilla-León (north-west Spain). Preventive Veterinary Medicine, Amsterdam, v. 29, p. 1-7, 1996.

SANTOS, F. et al. Molecular evaluation of the incidence of Ehrlichia canis, Anaplasma platys and Babesia spp. in dogs from Ribeirão Preto, Brazil. Veterinary Journal, London, v. 179, n. 1 , p. 145-148, 2009.

SHIPOV, A. et al. Prognostic indicators for canine monocytic ehrlichiosis. Veterinary Parasitology, Amsterdam, v. 153, p. 131-138, 2008.

SILVA, J. N. et al. Soroprevalência de anticorpos anti-E. canis em cães de Cuiabá, Mato Grosso. Revista Brasileira de Parasitologia Veterinária, São Paulo, v. 19, p. 108-111, 2010.

SOUSA, V. R. F. et al. Avaliação clínica e molecular de cães com erliquiose. Ciência Rural, Santa Maria, v. 40, p. 1309-1313, 2010.

SOUZA, B. M. P. S. et al. Prevalence of ehrlichial infection among dogs and ticks in Northeastern Brazil. Revista Brasileria Parasitologia Veterinária, Jaboticabal, v. 19, p. 8993, 2010. 
STICH, R.W. et al. Detection of Ehrlichia canis in canine carrier blood and in individual experimentally infected ticks with a p30-based PCR assay. Journal of Clinical

Microbiology, Washington, v. 40, n. 2, p. 540-546, 2002.

STICH, R. W. et al. Host surveys, ixodid tick biology and transmission scenarios as related to the tick-borne pathogen, Ehrlichia canis. Veterinary Parasitology, Amsterdam, v. 158, p. 256-273, 2008.

SZABÓ, M. P. J. et al. Ticks (Acari: Ixodidae) associated with domestic dogs in Franca region, São Paulo, Brazil. Experimental Applied Acarology, Amsterdam, v. 25, n. 10-11, p. 909916, 2001.

TRAPP, S. M. et al. Seroepidemiology of canine babesiosis and ehrlichiosis in a hospital population. Veterinary Parasitology, Amsterdam, v. 140, p. 223-230, 2006.

UENO, T. E. H. et al. Ehrlichia canis em cães atendidos em hospital veterinário de Botucatu, Estado de São Paulo, Brasil. Revista Brasileira de Parasitologia Veterinária, São Paulo, v. 18, n. 3, p. 57-61, 2009.

UNVER, A. et al. An acute severe ehrlichiosis in a dog experimentally infected with a new virulent strain of Ehrlichia canis. Clinical Microbiology and Infection, Oxford, v. 15, p. 1-3, 2008. Suppl. 1.

VAN CAMP, G.; CHAPELLE, S.; DE WACHTER, R. Amplification and sequencing of variable regions in bacterial 23S ribosomal RNA genes with conserved primer sequences. Current Microbiology v.27, p.147-51, 1993.

WANER, T. et al. Characterization of the subclinical phase of canine ehrlichiosis in experimentally infected beagle dogs. Veterinary Parasitology, Amsterdam, v. 69, p. 307$317,1997$.

WANER, T. et al. Demonstration of serum antiplatelet antibodies in experimental acute canine ehrlichiosis. Veterinary Immunology an Immunopathology, Amsterdam, v. 48, p. 177$182,1995$.

WANER, T. et al. Significance of serological testing for ehrlichial diseases in dogs with special emphasis on the diagnosis of canine monocytic ehrlichiosis caused by Ehrlichia canis.

Veterinary Parasitology, Amsterdam, v. 95, p. 1-15, 2001.

WANER, T. Hematopathological changes in dogs infected with Ehrlichia canis. Journal Veterinary Medical, Hamilton, v. 63, p. 19-22, 2008.

WEN, B. et al. Comparison of nested PCR with immunofluorescent-antibody assay detection of Ehrlichia canis infection the dogs treated with doxycicline. Journal of Clinical Microbiology, Washington, v. 35, n. 7, p. 1852-1855, 1997.

WERMELING, F.; KARLSSON, M. C. I.; McGAHA, T. L. An anatomical view on macrophages in tolerance. Autoimmunity Reviews, Amsterdam, v. 9, p. 49-52, 2009.

WOODY, B. J.; HOSKINS, J. D. Ehrlichial diseases of dogs. Veterinary Clinical North

American: Small Animal Practice, Oxford, v. 21, p. 75-98, 1991. 